\title{
Triggering receptor expressed on myeloid cells-1 as pediatric sepsis biomarker
}

\author{
João Victor Cabral',2* (), Maria Mariana Barros Melo da Silveira' (1), Amanda Tavares Xavier $^{3}$ (1), \\ Norma de Assunção ${ }^{2}$ (1), Dário Celestino Sobral Filho ${ }^{3}$ (1) , Dinaldo Cavalcanti de Oliveira' (1)
}

\section{SUMMARY}

OBJECTIVE: Triggering receptor expressed on myeloid cells-1 concentration can be used as a predictive, diagnostic, and prognostic marker in patients with sepsis. The objective of this study was to determine the validity of triggering receptor expressed on myeloid cells-1 levels as a biomarker of sepsis in pediatric patients.

METHODS: This was an integrative literature review. PubMed, ScienceDirect, LILACS, MEDLINE, and VHL databases were searched for papers published between 2015 and 2020, using the keywords triggering receptor expressed on myeloid cells-1, sepsis, and child. RESULTS: The review included ten studies, of which four used triggering receptor expressed on myeloid cells-1 as a predictive biomarker; four, as a diagnostic biomarker; and two, as a prognostic biomarker. A total of 1,409 and 1,628 patients were included in primary and review studies, respectively. There was a predominance of significant results for the validity of triggering receptor expressed on myeloid cells-1 levels in the prediction, diagnosis, and prognosis of sepsis in pediatric patients.

CONCLUSIONS: Triggering receptor expressed on myeloid cells-1 is a valid predictive, diagnostic, and prognostic biomarker of sepsis with good sensitivity and specificity in the pediatric population.

KEYWORDS: TREM-1 Protein. Sepsis. Child.

\section{INTRODUCTION}

Triggering receptor expressed on myeloid cells-1 (TREM-1) is a member of the immunoglobulin superfamily expressed on the surface of neutrophils, monocytes, and macrophages that plays a regulatory role in signaling pathways. TREM- 1 activation leads to the production of pro-inflammatory cytokines and chemokines, increases the expression of co-stimulatory molecules, and induces neutrophil degranulation and phagocytic activity. Concomitantly, the enzymatic cleavage of TREM-1 results in increased plasma levels of the soluble form of TREM-1 (sTREM-1) ${ }^{1}$.

Recently, serum sTREM-1 concentrations were found to be promising in the diagnosis of sepsis, pneumonia, meningitis, and fungal infections. However, results from different studies are inconsistent, especially in the pediatric population ${ }^{2}$. Sepsis is a common cause of morbidity and mortality in children. Clinical and laboratory signs of systemic inflammation are neither sensitive nor specific enough to be used in the diagnosis of sepsis ${ }^{3}$.

Infectious/inflammatory stimuli lead to an increase in the production of this receptor, so it can be a valuable diagnostic parameter when monitoring such conditions. Rios-Toro et al. ${ }^{4}$ showed that it is possible to consider sTREM- 1 as a biomarker of sepsis severity, considering the Sepsis-related Organ Failure Assessment (SOFA) and the Acute Physiology and Chronic Health Disease Classification System II (APACHE II) scores.

\footnotetext{
'Universidade Federal de Pernambuco, Postgraduate Program in Therapeutic Innovation - Recife (PE), Brazil.

${ }^{3}$ Universidade Federal de Pernambuco, Postgraduate Program in Health Sciences - Recife (PE), Brazil.

${ }^{2}$ State Health Secretariat of Pernambuco, Correia Picanço Hospital - Recife (PE), Brazil.

*Corresponding author: jvbcabral@gmail.com

Conflicts of interest: the authors declare there are no conflicts of interest. Funding: none.

Received on September 09, 2020. Accepted on September 26, 2020.
} 
This aspect is of great interest since many biomarkers are described in the literature for the diagnosis and prediction of sepsis outcome, but due to their unspecific characteristics and insufficient predictive value, their use in clinical practice is still a source of disagreement. Given the predictive, diagnostic, and prognostic value of TREM-1 levels in patients with sepsis, the implementation of routine TREM-1 measurements should be considered ${ }^{5}$, especially in cases of patients with bacterial infections $s^{6}$. The objective of this study was to determine the validity of TREM-1 as a biomarker of sepsis in pediatric patients.

\section{METHODS}

This was an integrative literature review conducted in six stages: theme identification and research question selection, establishment of inclusion and exclusion criteria, study search and result extraction, study evaluation, result interpretation, and synthesis of knowledge? .

The theme of the research question was based on the PICO strategy ( $\mathrm{P}$ - population: pediatric patients; I - interest: TREM-1 as a biomarker; $\mathrm{CO}$ - co-context: patients with sepsis), which resulted in the following question: Is TREM-1 a valid biomarker of sepsis in the pediatric population?

The inclusion criteria were as follows: papers on the use of TREM-1 as a biomarker of sepsis in a pediatric population, clinical and observational studies or systematic reviews, and studies published between 2015 and 2020. Papers on adult and/ or older populations, books, monographs, theses, dissertations, and editorials were excluded. The following databases were used: PubMed, ScienceDirect, Literatura Latino Americana y del Caribe em Ciências de La Salud (LILACS), Medical Literature Analysis and Retrieval System Online (MEDLINE), and the Virtual Health Library (VHL) Portal.

Sampling was conducted by surveying and analyzing publications using the descriptors selected from the Health Sciences Descriptors (DeCS), namely "TREM-1," "sepsis," and "child," and their respective Portuguese translations, crossed using the Boolean operator "and".

Initially, the titles and abstracts of the studies were read by two independent researchers and each researcher decided whether to include the evaluated study (first stage). Discordant cases were evaluated by a third researcher (second stage). Subsequently, the papers included by the three researchers were read in full to answer the review question (third stage).

The search resulted in 34 studies, which were evaluated according to the eligibility criteria, resulting in a sample of ten papers (Figure 1). The evaluation of level of evidence (LE) was guided by the determinations of the Oxford Center Evidence Based Medicine 8 . The extracted information was descriptive and directly related to the review question (Table 1).

\section{RESULTS}

Of the studies included, four used TREM-1 as a predictive biomarker ${ }^{9,11,14,15}$, four used it for diagnosis purposes ${ }^{6,10,12,13}$, and two, as a prognostic marker ${ }^{16,17}$ of sepsis in pediatric patients. As for the type of study, eight were primary surveys ${ }^{9-13,15-17}$ and two were systematic reviews ${ }^{6,14}$. As for the $\mathrm{LE}$, five papers were classified as $2 \mathrm{C}^{9,10,12,13,17}$, three as $3 \mathrm{~B}^{11,15,16}$, and two as $2 \mathrm{~A}^{6,14}$. As for the number of patients involved, there were 1,409 in the primary studies ${ }^{9-13,15-17}$ and $1,628^{6,14}$ in the review studies.

As for the interpretative analysis of primary study results, only one ${ }^{15}$ suggested that TREM-1 levels are not appropriate for detecting infections. The others ${ }^{9-13,16,17}$ showed significant results that validated the use of TREM-1 levels in the prediction, diagnosis, and prognosis of sepsis in children. The reviews concluded that TREM-1 is useful for predicting ${ }^{14}$ and diagnosing ${ }^{6}$ sepsis.

\section{DISCUSSION}

Sepsis is defined as a multisystemic failure with a significant risk of mortality. In recent years, several studies have been conducted to determine ways in which sepsis can be diagnosed and treated, using early interventions to reduce mortality in children. Increased survival can be a result of early recognition associated with adequate and targeted treatment ${ }^{18}$.

Biomarkers can be used to predict, diagnose, and prognose sepsis, in addition to monitoring therapeutic responses. The use of biomarkers must be based on critical analysis, and results should be interpreted according to the clinical status of the patients ${ }^{18}$.

Cordeiro et al. ${ }^{11}$ developed a mathematical model with 27 biomarkers for predicting adverse neonatal outcomes in premature infants. They found that TREM-1 levels was able to predict the incidence of sepsis (OR 0.99, 95\%CI 0.063-1.36). In serious situations, TREM-1 levels were found to be useful. ArizagaBallesteros et al. ${ }^{9}$ found that TREM-1 levels were a significant predictor of septic shock or death $(\mathrm{p}<0.0001)$, corroborating the findings of Şen et al. ${ }^{17}$. They showed that TREM-1 values were significantly higher in patients with septic shock $(129 \mathrm{pg} /$ $\mathrm{mL}$; min. 9.85; max. 494.90) than in those with severe sepsis $(105 \mathrm{pg} / \mathrm{mL}$; min. 8.21; max. 289.17) ( $\mathrm{p}=0.048)$.

Bellos et al. ${ }^{14}$ showed that TREM-1 levels were a useful biomarker of neonatal sepsis; however, due to the variations found, they suggest using it with caution (sensitivity $0.95,95 \% \mathrm{CI}$ 0.81-0.99; specificity $0.87,95 \%$ CI $0.56-0.97$ ).

Pontrelli et al. ${ }^{6}$ presented preliminary evidence on the role of TREM-1 in the diagnostic investigation of sepsis in newborns and children. However, it was not possible to obtain quantitative results due to the small number of studies, which included heterogeneous populations. 
Özdemir et al. ${ }^{15}$ found no significant difference in TREM-1 levels at days 1, 2, and 7 between patients with positive or negative blood culture results. The results suggest that TREM-1 is present at measurable levels on admission in children with febrile neutropenia, but it may not be appropriate to predict bloodstream infections. The expression of TREM-1 increased markedly in patients infected with Gram-positive and Gramnegative bacteria and fungi. Some studies in the literature showed that patients with septic shock have negative blood cultures, although they present with high TREM-1 values and progress to septic shock?

The use of predictive biomarkers in children with sepsis is promising but surrounded by challenges. To date, no single biomarker with predictive power in terms of patient outcome has been found. Based on the complexity of each patient's immune responses and genetic variations, it is unlikely that one biomarker alone can identify and stratify sepsis in a pediatric population ${ }^{19}$.
Saldir et al. ${ }^{10}$ showed that mean TREM-1 concentrations were significantly higher at the time of sepsis diagnosis in the septic group than in the non-septic group (median 985, IQR $576-1,400 \mathrm{pg} / \mathrm{mL}$ versus median 836.6 , IQR 702.2-944.8 pg/ $\mathrm{mL}, \mathrm{p}=0.028)$. Receiver operating characteristic curve analyses showed that TREM-1 levels had a significant area under the curve for the early identification of septic neonates (OR $0.97,95 \% \mathrm{CI}$ $0.931-0.998, \mathrm{p}<0.001)$. Univariate logistic regression analysis showed that increased TREM-1 levels was a strong predictor of neonatal sepsis (OR 126, 95\%CI 16.26-976.27, $\mathrm{p}<0.001$ ).

Al-Asy et al. ${ }^{12}$, despite not studying sepsis specifically, reported that children with diarrhea due to acute bacterial infection had significantly increased levels of serum TREM-1 on admission compared to patients with diarrhea due to non-bacterial infection and controls $(26.3667 \pm 16.8184$ $\mathrm{ng} / \mathrm{mL}$ versus $7.2267 \pm 6.4174 \mathrm{ng} / \mathrm{mL}$ vs. $6.7367 \pm 5.6479 \mathrm{ng} /$ $\mathrm{mL}$ and $39.9933 \pm 22.5260 \mathrm{ng} / \mathrm{mL}$ vs. $1.8533 \pm 1.7123$ versus $0.2840 \pm 0.1208 \mathrm{ng} / \mathrm{mL}$, respectively, $\mathrm{p}<0.05)$. TREM-1

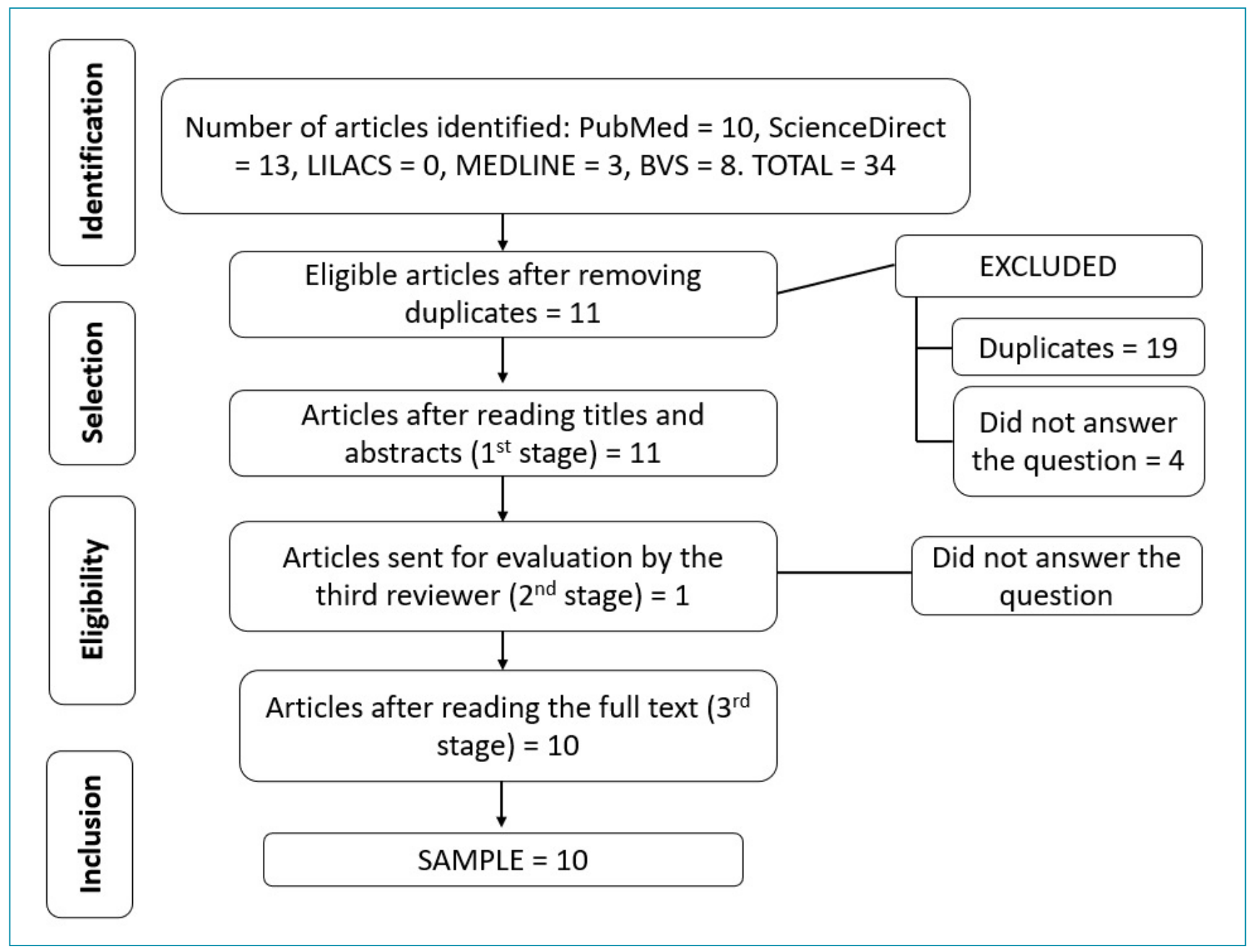

Figure 1. Flow diagram of the research strategy results and study selection. 
Table 1. Summary of studies by author, year, level of evidence, number of patients, and main results.

\begin{tabular}{|c|c|}
\hline $\begin{array}{l}\text { Author and year/Level of } \\
\text { evidence/Number of patients }\end{array}$ & Main results \\
\hline Arízaga-Ballesteros et al., 2015²/2C/71 & $\begin{array}{l}\text { In neonates with late-onset sepsis, sTREM-1 showed excellent predictive value } \\
(p<0.0001) \text { for septic shock/death, with a specificity and sensitivity of } 0.97 \\
\text { and } 0.78 \text {, respectively. }\end{array}$ \\
\hline Saldir et al., $2015^{10 / 2 C / 50}$ & $\begin{array}{l}\text { sTREM-1 levels were significantly higher }(p<0.001) \text { in neonates with sepsis } \\
\text { than in neonates who did not have sepsis. }\end{array}$ \\
\hline Cordeiro et al., 201611/3B/926 & $\begin{array}{l}\text { TREM-1 had a strong influence on building a model that showed significant } \\
\text { predictive value }(p<0.05) \text { for sepsis. }\end{array}$ \\
\hline Pontrelli et al., 20166/2A/961 & $\begin{array}{l}\text { sTREM-1 can be used as a diagnostic tool for pediatric sepsis, but the results } \\
\text { cannot be considered conclusive due to heterogeneity of the samples. }\end{array}$ \\
\hline Al-Asy et al., 201712/2C/80 & $\begin{array}{l}\text { Children with acute bacterial infection showed significantly increased }(p<0.05) \\
\text { sTREM-1 levels as compared to patients who had diarrhea without bacterial } \\
\text { infection, showing a specificity and sensitivity of } 93.7 \text { and } 94.3 \% \text {, respectively. }\end{array}$ \\
\hline Özdemir et al., 2018 & $\begin{array}{l}\text { Neonates with confirmed sepsis had significantly higher urine sTREM-1 } \\
\text { values }(p<0.05) \text { than those in the suspected sepsis group. The measurement } \\
\text { of this marker in the urine showed a sensitivity and specificity of } 0.90 \text { and } \\
0.78 \text {, respectively. }\end{array}$ \\
\hline Bellos et al., 201814/2A/667 & $\begin{array}{l}\text { sTREM-1 can be a useful biomarker for the prediction of neonatal sepsis, but } \\
\text { the small number of studies and the variation in the limit values negatively } \\
\text { impact its use in clinical practice. }\end{array}$ \\
\hline Özdemir et al., 201915/3B/57 & $\begin{array}{l}\text { There was no significant difference }(p>0.05) \text { in blood sTREM- } 1 \text { levels on days } \\
1,2 \text {, and } 7 \text { between patients with positive and negative blood culture results, } \\
\text { suggesting that this marker is not appropriate for predicting blood infections. }\end{array}$ \\
\hline Zhang et al., 202016/3B/76 & $\begin{array}{l}\text { The severe pneumonia group had significantly higher serum sTREM-1 levels } \\
\text { than the non-severe pneumonia and the control groups }(p<0.05) \text {. }\end{array}$ \\
\hline Şen et al., 202017/2C/87 & $\begin{array}{l}\text { TREM-1 values were significantly higher }(p=0.048) \text { in patients with septic } \\
\text { shock than in those with severe sepsis. }\end{array}$ \\
\hline
\end{tabular}

levels showed significantly high sensitivity $(93.7 \%)$ and specificity $(94.3 \%, 0.84-0.99)$ in predicting bacterial infection as a cause of acute diarrhea in children $(95 \% \mathrm{CI})$ at a cutoff value of $12.4 \mathrm{ng} / \mathrm{mL}$. Acute diarrhea is an important cause of mortality in children aged under five years ${ }^{20}$. Although rare, abdominal sepsis in children is potentially fatal.

Özdemir et al. ${ }^{13}$ reported that newborns in the positive culture group had significantly higher urine TREM-1 levels than those in the suspected sepsis group (sensitivity, 0.90 ; specificity, 0.78 ; positive predictive value, 0.68 ; negative predictive, value, 0.94).

Zhang et al. ${ }^{16}$ showed that the severe pneumonia group had significantly higher serum TREM-1 levels, APACHE II scores, and SOFA scores than the non-severe pneumonia group and the control group $(\mathrm{p}<0.05)$. Regarding children with severe pneumonia, the unresponsive group had significantly increased serum TREM-1 levels and SOFA scores at day 7 after admission, while the response group showed reduction in these values, with significant differences between the two groups $(\mathrm{p}<0.05)$.
A positive correlation was observed between TREM-1 levels and SOFA score $(\mathrm{p}<0.05)$.

\section{CONCLUSIONS}

Sepsis is a common condition in hospital settings that is especially severe in the pediatric population. Biomarkers can be used as important tools in the search for new management strategies. This review showed that TREM-1 levels are a valid predictive, diagnostic, and prognostic biomarker of sepsis, with good sensitivity and specificity in the pediatric population.

\section{AUTHORS" CONTRIBUTIONS}

JVBC: Conceptualization, Data Curation, Formal Analysis, Writing - Original Draft. MMBMS: Data Curation. ATX: Data Curation. NA: Data Curation. DCSF: Writing - Original Draft, Writing - Review \& Editing. DCO: Conceptualization, Data Curation, Formal Analysis, Writing - Original Draft. 


\section{REFERENCES}

1. Patoulias D, Kalogirou MS, Patoulias I. Triggering Receptor Expressed on Myeloid Cells-1 (TREM-1) and its soluble in the plasma form (sTREM-1) as a diagnostic biomarker in neonatal sepsis. Folia Med Cracov. 2018;58(2):15-9. https:// doi.org/10.24425/fmc.2018.124655

2. Jedynak M, Siemiatkowski A, Milewski R, Mroczko B, Szmitkowski M. Diagnostic effectiveness of soluble triggering receptor expressed on myeloid cells-1 in sepsis, severe sepsis and septic shock. Arch Med Sci. 2019;15(3):713-21. https:// doi.org/10.5114/aoms.2018.73090

3. Soud DEM, Amin OAl, Amin AAl. New era "soluble triggering receptor expressed on myeloid cells-I" as a marker for early detection of infection in trauma patients. Egypt J Anaesth. 2011;27 (4):267-72. https://doi.org/10.1016/j.egja.2011.07.002

4. Ríos-Toro JJ, Márquez-Coello M, García-Álvarez JM, MartínAspas A, Rivera-Fernández R, De Benito AS, et al. Soluble membrane receptors, interleukin 6 , procalcitonin and $C$ reactive protein as prognostic markers in patients with severe sepsis and septic shock. PLoS One. 2017;12(4):e0175254. https:// doi.org/10.1371/journal.pone.0175254

5. Brenner $T$, Uhle $F$, Fleming $T$, Wieland $M$, Schmoch $T$, Schmitt $F$, et al. Soluble TREM-1 as a diagnostic and prognostic biomarker in patients with septic shock: an observational clinical study. Biomarkers. 2017;22(1):63-9. https://doi.org/10.1080/1354750X.2016.1204005

6. Pontrelli G, De Crescenzo F, Buzzetti R, Calò Carducci F, Jenkner $A$, Amodio D, et al. Diagnostic value of soluble triggering receptor expressed on myeloid cells in paediatric sepsis: A systematic review. Ital J Pediatr. 2016;42 (44):1-10. https:// doi.org/10.1186/s13052-016-0242-y

7. Mendes KDS, Silveira RCCP, Galvão CM. Use of bibliographic reference manager in the selection of primary studies in an integrative reviews. Enferm. 2019;28:e20170204. https://doi. org/10.1590/1980-265X-TCE-2017-0204

8. Oxford Centre for Evidence-Based Medicine. Levels of evidence [Internet]. 2009; [cited on Aug. 20, 2020]. Available in: http:// www.cebm.net/oxfordcentre-evidence-based-medicine-levelsevidencemarch- 2009/

9. Arízaga-Ballesteros V, Alcorta-García MR, Lázaro-Martínez LC, Amézquita-Gómez JA, Alanís-Cajero JM, Villela L, et al. Can sTREM-1 predict septic shock \& death in late-onset neonatal sepsis? A pilot study. Int J Infect Dis. 2015;30:27-32. https:// doi.org/10.1016/j.jijid.2014.10.013

10. Saldir M, Tunc T, Cekmez F, Cetinkaya M, Kalayci T, Fidanci K, et al. Endocan and soluble triggering receptor expressed on Myeloid Cells-1 as novel markers for neonatal sepsis. Pediatr Neonatol. 2015;56(6):415-21. https://doi.org/10.1016/j.pedneo.2015.03.006
11. Cordeiro CN, Savva Y, Vaidya D, Argani CH, Hong X, Wang $X$, et al. Mathematical modeling of the biomarker milieu to characterize preterm birth and predict adverse neonatal outcomes. Am J Reprod Immunol. 2016;75(5):594-601. https://doi.org/10.1111/aji.12502

12. Al-Asy HM, Gamal RM, Albaset AMA, Elsanosy MG, Mabrouk MM. New diagnostic biomarker in acute diarrhea due to bacterial infection in children. Int J Pediatr Adolesc Med. 2017;4(2):75-80. https://doi.org/10.1016/j. ijpam.2016.12.004

13. Ozdemir SA, Ozer EA, llhan O, Sutcuoglu S, Tatlı M. Diagnostic value of urine soluble triggering receptor expressed on myeloid cells (sTREM-1) for late-onset neonatal sepsis in infected preterm neonates. J Int Med Res. 2018;46(4):1606-16. https:// doi.org/10.1177/0300060517749131

14. Bellos I, Fitrou G, Daskalakis G, Thomakos N, Papantoniou N, Pergialiotis V. Soluble TREM-1 as a predictive factor of neonatal sepsis: a meta-analysis. Inflamm Res. 2018;67(7):571-8. https:// doi.org/10.1007/s00011-018-1149-4

15. Özdemir ZC, Düzenli-Kar Y, Canik A, Küskü-Kiraz Z, Özen $\mathrm{H}$, Bör $\mathrm{O}$. The predictive value of procalcitonin, C-reactive protein, presepsin, and soluble-triggering receptor expressed on myeloid cell levels in bloodstream infections in pediatric patients with febrile neutropenia. Turk J Pediatr. 2019;61(3):359-67. https://doi.org/10.24953/ turkjped.2019.03.007

16. Zhang HF, Zhang $X$, Sha $Y X$, Zhou HQ, Pan JH, Xun X, et al. Value of STREM-1 in serum and bronchoalveolar lavage fluid, APACHE II score, and SOFA score in evaluating the conditions and prognosis of children with severe pneumonia. Zhongguo Dang Dai Er Ke Za Zhi. 2020;22(6):626-31. https://doi. org/10.7499/j.issn.1008-8830.1912134

17. Şen S, Kamit F, İşgüder R, Yazıcı P, Şahbudak Bal1 Z, Devrim I, Bayram SN. Surface TREM-1 as a Prognostic Biomarker in Pediatric Sepsis. Indian J Pediatr. 2021;88(2):134-40. https:// doi.org/10.1007/s12098-020-03355-3

18. Garcia PCR, Tonial CT, Piva JP. Septic shock in pediatrics: the state-of-the-art. J Pediatr (Rio J). 2020;96(Suppl 1):87-98. https://doi.org/10.1016/j.jped.2019.10.007

19. Lanziotti VS, Póvoa P, Soares M, Silva JR, Barbosa AP, Salluh Jl. Use of biomarkers in pediatric sepsis: literature review. Rev Bras Ter Intensiva. 2016;28(4):472-82. https://doi.org/10.5935/0103507X.20160080

20. Gouveia MAC, Lins MTC, Silva GAP. Acute diarrhea with blood: diagnosis and drug treatment. J Pediatr (Rio J). 2020;96(Suppl 1):20-8. https://doi.org/10.1016/j.jped.2019.08.006 